\title{
Profile of osteopathic practice in Spain: results from a standardized data collection study
}

\author{
Gerard Alvarez Bustins ${ }^{1,2,4^{*}}$, Pedro-Victor López Plaza ${ }^{3,4}$ and Sonia Roura Carvajal ${ }^{1,4}$
}

\begin{abstract}
Background: There is limited research regarding patients' profiles and consumer attitudes and habits of osteopathy in Spain. The purpose of this study was to profile patients who regularly receive osteopathic care in Spain using an internationally developed standardized data collection tool.

Method: During the period between April 2014 and December 2015, a UK-developed standardized data collection tool was distributed to Spanish osteopaths who voluntarily agreed to participate in this cross-sectional study.

Results: Thirty-six osteopaths participated in this study and returned a total of 314 completed datasets. Of 314 patients, 61\% were women and 39\% were men, with a mean age of 40 years (SD 17.02 years, range 0 to 83 years). Forty-four percent were full-time salaried workers, and in $78 \%$ of cases, receiving osteopathic treatment was the patient's own choice. Chronic spinal pain presentations were the most frequent reasons for consultation. Seventyfive percent of patients presented with a coexisting condition, mainly gastrointestinal disorders and headaches. The main treatment approach consisted of mobilization techniques, followed by soft tissue, cranial and high velocity thrust techniques. Improvement or resolution of the complaint was experienced by $93 \%$ of patients after a small number of sessions. Adverse events were minor and occurred in $7 \%$ of all cases.

Conclusion: This is the first study carried out in Spain analyzing the profile of patients who receive osteopathic care. The typical patient who receives osteopathic care in Spain is middle-aged, presents mainly with chronic spinal pain, and voluntarily seeks osteopathic treatment. Osteopathic treatment produces a significant improvement in the majority of cases with a low rate of minor adverse events reported.
\end{abstract}

Keywords: Osteopathy, Osteopathic medicine, Cross-sectional survey, Standardized data collection, Scope of practice, Clinical presentations

\section{Background}

Osteopaths first started practicing in Spain in the 1980s. Since then, the practice of osteopathy in Spain has significantly developed. The first professional training and education programs in osteopathy began in 1987 and were taught by French and Belgian instructors [1]. Osteopathy is not regulated in Spain as a healthcare profession as it's not included on the Law of Arrangement of the Sanitary Professions

\footnotetext{
* Correspondence: gerardalv@gmail.com

${ }^{1}$ Centre for Osteopathic Medicine - C.O.ME. Collaboration, Spain National Center, Clinical-based Human Research Department, Barcelona, Spain

${ }^{2}$ Iberoamerican Cochrane Centre - Biomedical Research Institute Sant Pau, IIB Sant Pau, Barcelona, Spain

Full list of author information is available at the end of the article
}

(LOPS 44/2003). In the other hand, the Ministerial Order $(2135 / 2008)$ that establish the educational curriculum of the physiotherapy degree mention osteopathy as a technique that undergraduates shall know. However, both the standards and scope of practice of osteopathy in Spain lack formal recognition in the regulatory and legislative domains [2]. This situation has resulted in the co-existence of two recognized groups including 'osteopaths' (i.e., practitioners without prior health science degrees), and osteopathphysiotherapists (i.e., practitioners with prior health science degrees, typically in physiotherapy). Although the osteopath-physiotherapist group represents the majority of osteopaths practicing in Spain, there are 
other groups of practitioners with very diverse training and educational backgrounds. This 'lawless' situation has thereby fostered the emergence of numerous qualifications and professional associations representing different groups of osteopaths.

Additionally, there is limited research regarding the profiles of people who seek osteopathic treatment in Spain. In May 2008, the Observatory of Natural Therapies published an independent study, sponsored by three natural therapy organizations, on the use and habits of consumers of natural therapies in Spain [3] (Additional file 1). In this study, 2000 people aged between 16 and 65 years were interviewed. The results showed that osteopathy was known by $32 \%$ of the population and that $8.2 \%$ used it regularly. In 2011, the Spanish Ministry of Health, Social Policy and Equality published the report "Analysis of the situation of natural therapies" [4], which analyzed 139 techniques carried out within the natural therapies scope by assessing the existing scientific evidence, use and legal framework associated with these techniques in Spain and other countries. This report, which received expert contributions from several professional registers and organizations, profiled osteopathy as a complementary and alternative medicine and classified it under the category "Manipulative and body based therapies"; however, this report failed to provide additional data regarding natural therapy consumer use and habits beyond that submitted in 2008 by the Natural Therapies Observatory [3].

In 2009, the National Council for Osteopathic Research (NCOR) in the United Kingdom (UK) developed and piloted a Standardized Data Collection tool (SDC) to profile the demographics and clinical presentations of patients receiving osteopathic care [5]. The study characterized osteopathic practice in the UK to establish standards for audit activities, obtain relevant information for the profession and develop a resource for research purposes. The study demonstrated that the SDC tool was able to generate a substantial amount of high quality information and was suitable for widespread use. For example, it was able to provide information about patients' demographic characteristics, presenting symptoms, patient management and treatment, and results obtained. In the last few years, some studies have been conducted in different countries to trace the profiles of both the professionals and patients who receive osteopathic care [6-10]. The SDC tool was used in some of these studies.

The primary objective of this study was to profile patients who regularly receive osteopathic care in Spain using the "SDC tool" developed by Fawkes and colleagues, which has been modified for a Spanish population. A secondary objective was to describe the professional profile of active osteopaths in Spain through a parallel survey designed specifically for this purpose.

\section{Methods \\ Participants}

During the period between April 2014 and December 2015, the SDC tool was distributed to all osteopaths who voluntarily agreed to participate in this crosssectional study. The pragmatic eligibility criteria included any professional who named their practice as osteopathy. For participant recruitment, a three-step process was established. First, the cooperation of all associations, Registers and schools of osteopathy in Spain country was required. At the same time, the research team launched an internet-based information and awareness campaign on social networks (Twitter and Facebook) specially focused on Spanish osteopathic community groups. An explanatory video on how to participate and complete the form was also distributed (https://vimeo.com/105709291). Through these channels, a contact email address and a specific acceptation form to participate was provided. When acceptance forms were received, the research team provided osteopaths with a study information sheet and instructions to provide to their patients so that they would be fully informed about the purpose of the study (Additional file 2). Two reminders were scheduled for those osteopaths who did not return any completed survey after having agreed to participate. To maintain anonymity and confidentiality, each osteopath was allocated a unique ID code to which they could add a sequential code $(01,02$.) for the patient identifier. The Institutional Review Board of Barcelona Osteopathic Foundation approved the study (FOB04140001). Informed consent was assumed by participation in the study.

\section{The questionnaire}

Once authorized by NCOR, the extended version of the SDC tool was translated and cross-culturally adapted to Spanish. The translation process involved all members of the research team and was completed in 4 steps. i) forward translation into Spanish (PP) ii) backward translation into English verifying equivalency to the original meanings (GA \& SR) iii) and piloting the questions on a sample of 5 osteopaths and iv) modification of the forward translation after pilot feedback (SR). The questionnaire was uploaded to an internet-based survey platform (SurveyMonkey Europe - Dublin, Ireland) (Additional file 3).

The study form had three parts, those corresponding to the 1st and 2nd consultations and the last consultation in the data collection phase. The modified SDC Tool consisted of 47 items separated in different blocks that covered information about healthcare quality and treatment during the osteopathic intervention process. 
I. Initial consultation for a new episode: Comprised of 23 questions related to the patient's medical history, lifestyle, previous treatments, presence of pain, anatomical location of their symptoms and reasons for consulting an osteopath.

II. Management and Treatment: Comprised of 2 questions regarding the initial treatment and management of the patient and included treatment approaches used after the first consultation.

III. Information and consent: Comprised of 7 questions covering information regarding consent and its associated characteristics.

IV. Second Consultation: Comprised of 5 questions about the outcomes and approach of subsequent appointments regarding the treatment and the duration of the visit.

V. Last consultation for the treatment of the episode: Comprised of 10 questions related to the state of the patient at the end of the data collection period, total number of treatments received, and the evolution and quantification of the initial symptoms.

The symptom area(s) where the patient reported their complaints was considered the reason for consultation, and multiple sites were allowed. The osteopath chose a maximum of 4 symptom areas ranked by importance to the patient (considered as the clinical presentation). For pain reporting, a numerical rating scale (NRS) was used [11]. Patients were asked to range their pain in a $0-10$ scale, with 0 representing the absence of pain and 10 the worst pain possible. A self-reported improvement was also recorded.

For those osteopaths who requested the survey in paper format, it was sent along with detailed return instructions and a prepaid envelope. Osteopaths recorded information from 10 new consecutive patients to avoid selection bias. In addition, the osteopaths received a second survey with 20 questions covering their professional profile. These 20 questions collected data among the following 3 blocks: pretraining, osteopathic studies, and workplace location and characteristics (Additional file 4).

\section{Data management and statistical analysis}

Data obtained from the on-line survey were automatically exported to a spreadsheet (Microsoft Excel ${ }^{\circ}$ version 15.21.1 - Microsoft Ibérica, Madrid -Spain). Data obtained in paper format were manually entered into the same spreadsheet by SR who was also responsible of the data analysis. All of the information collected (either from complete and incomplete forms) were analyzed. The responses were coded quantitatively to enable a simple descriptive statistical analysis. The total number of answers available for each question are reported in the following sections.

\section{Results}

Of the 61 osteopaths who agreed to participate in the study, 36 returned the questionnaires from which a total of 314 datasets/patients were analyzed (8.7 patients for each osteopath on average). Eighty-three percent of the compiled questionnaires originated from the same region of the country (Catalonia). Two hundred forty-five patients completed treatment during the data collection period, and 75 (24\%) did not finish the plan of care for unknown reasons. Among the three parts of the SDC tool, we collected information about the first visit from 314 patients, about the second visit from 266 (85\%) patients and regarding the last visit from 248 (79\%) patients. Concerning the quality of the responses, some of the forms were delivered incomplete (partially filled). Notwithstanding this, the unanswered questions did not follow a specific pattern that can suggest lack of interest or insufficient training methods.

\section{Patients' demographic information}

Patient demographic data are shown on Table 1. From 314 datasets, $61 \%(n=192)$ were women versus $39 \%$ men $(n=122)$, and all participants had a mean age of 40 years (SD 17.02 years, range 0 to 83 years). The majority of patients $(77 \%, n=241)$ were adults ( $>18$ years), whereas $15 \%(n=47)$ were children $(<18$ years $)$, of whom $10 \%(n=15)$ were under the age of 1 .

Regarding the patient employment profile, $44 \%$ ( $n=$ 137) of the respondents were full-time salaried workers. In $78 \%(n=244)$ of the cases, receiving osteopathic treatment was the patient's own choice. The findings of this study reflected that the remaining $22 \%(n=68)$ of referrals were provided by other health professionals including $23 \%$ from general practitioners, $18 \%$ from physiotherapists, $16 \%$ from orthopedic consultants, $7 \%$ from podiatrists and a minor percentage from other professionals such as gynecologists, optometrists, physical trainers, pediatricians, neurologists, psychologists, acupuncturists, osteopaths, internal medicine specialists, dentists and insurance companies. Notwithstanding this, the main source of referrals for patients was in most cases attributed to word-of-mouth recommendations (76\%, $n=239)$. The patient paid out of pocket for treatment in $91 \%(n=284)$ of the cases.

Seventy-three percent $(n=229)$ of the cases had not previously received osteopathic treatment, and the main reasons to initiate treatment were personal recommendation or direct referral $(75 \%, n=235)$, previous unsuccessful treatments $(34 \%, n=108)$ or an individual choice to receive osteopathic treatment $(30 \%, n=93)$ (Table 1$)$. Eleven percent of patients reported that they had already received prior treatment for the same complaint; including chiropractic, massage, physiotherapy, acupuncture, 
Table 1 Patients socio-demographic Characteristics

\begin{tabular}{|c|c|c|}
\hline & $\%$ & $\mathrm{n}$ \\
\hline Sex & & 314 \\
\hline Female & $61 \%$ & 192 \\
\hline Male & $39 \%$ & 122 \\
\hline Age (years) & & 40 (mean) \\
\hline Employment situation & & 314 \\
\hline Full-time employee & $44 \%$ & 137 \\
\hline Student & $17 \%$ & 54 \\
\hline Self-employed & $14 \%$ & 43 \\
\hline Retirement & $8 \%$ & 27 \\
\hline Unemployed & $5 \%$ & 16 \\
\hline $\begin{array}{l}\text { Other (Employee temporary } \\
\text { part-time, domestic } \\
\text { employment, pensioner) }\end{array}$ & $12 \%$ & 37 \\
\hline Referral Source & & 313 \\
\hline Patient's own choice & $78 \%$ & 244 \\
\hline Health care professional & $21 \%$ & 68 \\
\hline Other & $1 \%$ & 1 \\
\hline Previous Osteopathic treatment & & 313 \\
\hline No & $73 \%$ & 229 \\
\hline Yes & $27 \%$ & 84 \\
\hline \multicolumn{3}{|l|}{ Osteopathic reason for consultation } \\
\hline Recommendation or Reference & $75 \%$ & 235 \\
\hline Previous unsuccessful treatment & $34 \%$ & 108 \\
\hline $\begin{array}{l}\text { Their choice to receive } \\
\text { osteopathic treatment }\end{array}$ & $30 \%$ & 93 \\
\hline $\begin{array}{l}\text { Treatment options other } \\
\text { than medication }\end{array}$ & $26 \%$ & 81 \\
\hline Manual treatment search & $20 \%$ & 64 \\
\hline Personal search & $16 \%$ & 49 \\
\hline $\begin{array}{l}\text { Previous Osteopathic } \\
\text { treatment experience }\end{array}$ & $10 \%$ & 31 \\
\hline Alternative to surgery & $5 \%$ & 16 \\
\hline $\begin{array}{l}\text { Do not desire treatment } \\
\text { programmes from } \\
\text { Social Security services }\end{array}$ & $4 \%$ & 12 \\
\hline $\begin{array}{l}\text { Awaiting for rehabilitation } \\
\text { covered by the } \\
\text { Social Security service }\end{array}$ & $2 \%$ & 7 \\
\hline Other & $2 \%$ & 7 \\
\hline
\end{tabular}

Bach flower remedies, neural therapy, diathermy, podiatry, optometry, speech therapy and steroid injections.

The waiting time to be examined by an osteopath did not exceed one week as reported by $75 \%(n=236)$ of patients. The remaining $25 \%(n=76)$ had to wait more than 8 days. The median number of medical consultations patients had undergone before receiving osteopathic treatment was 2 visits.

\section{Reason for consultation (clinical presentation)}

The three most frequent complaints reported were symptoms in the cervical area (20\%) followed by the lumbar area (13\%) and the head and facial area (13\%) (Table 2). Eighty-three percent of patients included in the study expressed multiple complaints at their first consultation (55\% presented two co-morbid conditions and $31 \%$ presented more than 3). Comorbidities followed the same distribution and included cervical (25\%), lumbar (18\%) and head and facial area $(11 \%)$ conditions.

Thirty-eight percent $(n=119)$ of patients reported suffering from their complaint for over a year, $9 \%(n=$ 27) between 6 and 12 months, 27\% $(n=84)$ between 1 and 6 months and 27\% $(n=83)$ less than one month. Forty-nine percent $(n=152)$ of patients reported that it was the first time they had suffered from their complaint, whereas $35 \%(n=111)$ had experienced it on 4 or more occasions. Eighty-nine percent $(n=278)$ had not taken time off from work despite the problem. The mean value of the degree of pain reported at the start of treatment was of 6 points (SD 2.2) on the pain assessment scale (NRS).

Seventy-five percent of patients had medical history accounts $(n=234)$ vs. $25 \%(n=79)$ without accounts. The most frequent medical history conditions were gastrointestinal $(12 \%, n=29)$, migraines $(11 \%, n=25)$, anxiety $(9 \%, n=22)$ and arterial hypertension $(9 \%, n=21)$.

\section{Therapeutic approaches}

In $96 \%(n=301)$ of patients included in the study, osteopathic treatment was considered appropriate. The most frequently used techniques during the first consultation were mobilization techniques $(60 \%)$, soft tissue techniques (57\%), high velocity technique (HVT - thrust techniques) (52\%) and cranial techniques (46\%). At the follow-up consultations, the most commonly used techniques were mobilization techniques (61\%), cranial techniques (54\%), soft tissue techniques (52\%), and functional techniques (42\%) (Table 3).

The time spent on each treatment session was divided between visits of $<30 \mathrm{~min}$, between 30 and 45 , between 45 and 60 or $>60 \mathrm{~min}$. The frequency of each session duration is shown in Table 4.

In $80 \%$ of the cases, the therapists asked for patient consent before providing osteopathic treatment. Of the consent-based cases, 33\% were performed verbally, $21 \%$ were written and $46 \%$ were both verbal and written.

In the majority of cases, patients were informed about the different treatment options (70\%), the possible risks and side effects of the treatment (85\%), the expected response to treatment (4\%), the approximate number of sessions required (72\%), ways to avoid relapse in the future (66\%) and 
Table 2 Reason for consultation (clinical presentation location) $n=311$

\begin{tabular}{ll}
\hline & $\%$ \\
\hline Neck-cervical & $20 \%$ \\
Lumbar & $13 \%$ \\
Head- Face areas & $13 \%$ \\
Sl/pelvis/groin & $9 \%$ \\
Shoulder & $7 \%$ \\
Knee & $5 \%$ \\
Thoracic spine & $5 \%$ \\
Chest, Rib cage & $4 \%$ \\
Hip & $4 \%$ \\
Foot & $3 \%$ \\
Abdomen & $3 \%$ \\
Ankle & $3 \%$ \\
Gluteal region & $3 \%$ \\
Elbow & $2 \%$ \\
Hand & $1 \%$ \\
TMJ & $1 \%$ \\
Other & $1 \%$ \\
Wrist & $1 \%$ \\
Arm & $1 \%$ \\
Muscle & $0 \%$ \\
Folf & $0 \%$ \\
\hline SISarm & $0 \%$ \\
\hline
\end{tabular}

SI Sacroiliac joint, TMJ Temporomandibular joint

an explanation of the clinical problem they presented (97\%). In most cases, patients received counseling on their lifestyle habits, diet, and physical activity (66\%), and only in few cases (9\%) were other aspects were recommended.

\section{Treatment results}

After the first consultation, patients reported that they felt "much better" in $25 \%$ of cases, "improving" in 52\% and "no better or worse" in 15\%. At the end of treatment, $72 \%$ of patient datasets included in the study reported being "much better" or "better than ever", as described in Table 5. The mean value on the NRS at the end of treatment was of 1.6 (SD 1.8) (Table 5).

Seventy-three percent $(n=194)$ of patients did not report any side effects to the treatment after the first visit, whereas the remaining 27\% $(n=99)$ mainly experienced fatigue and / or increased pain-related side effects. At the end of treatment, $93 \%(n=224)$ of patients did not have any adverse effects.

Among the 248 patients who finished their plan of care during the study period, the number of treatment sessions provided ranged between 1 and 3 in $57 \%$ of the cases, 3-6 in
$39 \%$ of the cases, $6-9$ in $2 \%$ of the cases and $>9$ in $2 \%$ of the cases. The median number of consultations per patient was 3 consultations, and the treatment duration ranged from 1 to 3 months in $54 \%$ of cases, less than one month in $31 \%$ of cases and more than 4 months in $15 \%$ of cases.

Sixty-eight percent $(n=168)$ of patients completed treatment during the time period in which the study was conducted. Seventeen percent $(n=42)$ were still receiving osteopathic care upon completion of the study, and 15\% $(n=38)$ abandoned or terminated their plan of care for various reasons (e.g., illness, funding problems).

Upon the patients' last visits within the study period, $25 \%$ had completed the treatment plan, $35 \%$ voluntarily chose to return for a check-up, 17\% continued treatment, and 23\% were referred to some further diagnostic process or resumed previous treatments.

\section{Osteopaths demographics}

The mean age of the osteopaths participating in the study was 36.6 years (SD 7.65 years, range 27 to 70 years), and all held university qualifications prior to their osteopathy studies. The demographic and academic characteristics of the osteopaths are shown in Table 6. In reference to the participants' osteopathy education and training, 61\% $(n=22)$ had more than $1500 \mathrm{~h}, 36 \%(n=$ 13) had between 1000 and 1500 training hours, and 3\% $(\mathrm{n}=1)$ had less than $500 \mathrm{~h}$. Ninety-seven percent $(n=$ 35 ) of the osteopaths worked in a private practice of which $71 \%(n=25)$ did so in their own practice. Sixtyfour percent $(n=23)$ worked with other osteopaths, and $61 \%(\mathrm{n}=22)$ were part of a multidisciplinary team. Eighty percent $(n=29)$ of osteopaths worked exclusively as an osteopath, and $20 \%(n=7)$ of the therapists combined their activity with other professional activities. Ninety-four percent of the participants reported to treat patients with musculoskeletal complaints, $47 \%$ pediatric patients, 39\% obstetric patients, 33\% gynecological problems and $11 \%$ sport related injuries (Table 6).

Fifty-five percent of osteopaths were registered to some osteopathic register or professional association. All of these osteopaths were from Registro de los Osteopatas Españoles (ROE) except one from the General Osteopathic Council (GOsC).

\section{Discussion}

To the best of our knowledge, this is the first study attempting to describe the profile of osteopathic practice in Spain. The main aim was to determine not only the profile of patients who receive osteopathic care in Spain but also the main features of the service provided. Furthermore, it was of interest to record the profile of the professionals who participated in the study. The SDC tool offers extensive information about the patients' 
Table 3 Techniques Approaches

\begin{tabular}{llll}
\hline First Visit & $n=301$ & Follow-up visits & $n=266$ \\
\hline mobilization techniques & $60 \%$ & mobilization techniques & $61 \%$ \\
Soft tissues & $57 \%$ & Cranial Techniques & $54 \%$ \\
HVT & $52 \%$ & Soft tissues & $52 \%$ \\
Cranial Techniques & $46 \%$ & Functional Techniques & $42 \%$ \\
Functional Techniques & $38 \%$ & HVT & $39 \%$ \\
Counseling on daily lifestyle and habits & $31 \%$ & Visceral Techniques & $29 \%$ \\
Visceral Techniques & $28 \%$ & Counseling on daily lifestyle and habits \\
Patient education & $23 \%$ & Patient education \\
Counterstrain & $19 \%$ & Muscle Energy technique \\
Muscle Energy technique & $9 \%$ & Counterstrain & $24 \%$ \\
Contraction/Relaxation/Stretching & $8 \%$ & Contraction/Relaxation/Stretching \\
Physical activity & $7 \%$ & Relaxation techniques \\
Other & $6 \%$ & Physical activity & $20 \%$ \\
Diet & $4 \%$ & Other & $12 \%$ \\
Acupuncture & $3 \%$ & Diet & $11 \%$ \\
Relaxation techniques & $2 \%$ & Acupuncture \\
Hands off & $1 \%$ & Hands off & $7 \%$ \\
Orthopedic equipment & $1 \%$ & Orthopedic equipment & $7 \%$ \\
Infiltration & $0 \%$ & Infiltration & $6 \%$ \\
\hline
\end{tabular}

HVT high velocity technique

demographic characteristics, their reported symptoms, the osteopathic management plan derived therefrom and the way in which the service is provided.

The socioeconomic profile of the patient seeking osteopathic care in Spain mostly corresponds to people (women $>$ men) of middle age (mean $=40$ years) who are full-time employees. These results agree with the only study previously published in Spain [3] and the studies by Burke et al. [6] and Fawkes et al. [7] performed in Australia and UK, respectively (Table 7). This profile has also been reported in patients who receive complementary and / or alternative medicines and other self-care activities $[12,13]$.

In Spain, osteopathy is mainly provided within the private healthcare sector and generally is a health service not covered either by the National Health System or by most health insurance companies. It was noted that although the majority of patients were adults, $15 \%$ were patients under 14 years of age, showing the interest and use of parents in Complementary and Alternative Medicine (CAM) in Europe [14-17].

The results revealed that a large population of patients included in this study had never received osteopathic care. The proportion of referrals from other healthcare professionals was found to be small. The choice to seek and undergo osteopathic treatment is usually personal and pursued as an alternative to previous unsuccessful treatments. This finding is supported by research focusing specifically on CAM use by pain sufferers, which described patients' opinions as dissatisfaction with their general practitioners' (GPs) availability, wait time, or lack of benefit from conventional medical treatments for back pain [13].

The main reason for receiving osteopathic care in Spain is related to musculoskeletal problems, mainly in the cervical and lumbar spine. These outcomes were also noted in similar studies conducted in other countries [6-10].

Table 4 Time spent in consultation

\begin{tabular}{llllll}
\hline $1^{\text {st }}$ Visit & & $n=312$ & Successive visits & $n=263$ \\
\hline Less than 30 minuts & $1 \%$ & 3 & Less than 30 minuts & $5 \%$ & 14 \\
Between 30 and 45 minuts & $15 \%$ & 47 & Between 30 and 45 minuts & $25 \%$ & 67 \\
Between 45 and 60 minuts & $58 \%$ & 180 & Between 45 and 60 minuts & $68 \%$ & 179 \\
More than 60 minuts & $26 \%$ & 82 & More than 60 minuts & $1 \%$ \\
\hline
\end{tabular}


Table 5 Results obtained \& NRS scale

\begin{tabular}{llllll}
\hline $2^{\text {nd }}$ Visit results & & $n=266$ & Last Visit results & & $n=244$ \\
\hline Better than ever & $5 \%$ & 13 & Better than ever & $17 \%$ & 42 \\
Much better & $25 \%$ & 66 & Much better & $55 \%$ & 134 \\
Improved & $52 \%$ & 137 & Improved & $21 \%$ & 52 \\
No better or worse & $15 \%$ & 43 & No better or worse & $6 \%$ & 14 \\
Worst & $2 \%$ & 5 & Worst & $0 \%$ & 1 \\
Far worse & $1 \%$ & 2 & Far worse & $0 \%$ & 1 \\
Worse than ever & $0 \%$ & 0 & Worse than ever & $0 \%$ & 0 \\
Average score on NRS scale & & & \\
\multicolumn{2}{l}{$\begin{array}{l}\text { Pretreatment } \\
\text { Post-treatment }\end{array}$} & & & 6
\end{tabular}

The use of CAM for back pain was recently extensively evaluated by Murthy et al. [13] Osteopathy was among the 4 CAM modalities assessed in that study along with acupuncture, chiropractic and massage. According to Murthy and colleagues [13], the prevalence of osteopathic treatment for back pain ranged from 4.1 to $48.4 \%$ (mean: 17.3\%; median: $8.4 \%$ ) as reported by four population studies drawing on fieldwork with large samples.

Recent research on the prevalence of spinal pain in Spain demonstrated that, after a period of stability between the years 2004/5 and 2008/9 [18], there was increase in the prevalence during between 2008/9 and $2011 / 12$, with values of $5.4 \%$ for neck pain and $8.56 \%$ for low back pain [19].According to Palacios-Ceña and colleagues [19], this increase can be partially explained by the economic crisis suffered in Spain in recent years.

Table 6 Therapists socio-demographic Characteristics

\begin{tabular}{lll}
\hline & $\%$ & $\mathrm{n}$ \\
\hline Sex & $53 \%$ & 36 \\
Male & $47 \%$ & 19 \\
Female & 36.7 (mean) - 7.65 SD & 17 \\
Age (years) & $100 \%$ & \\
Previous Studies & $88.5 \%$ & 31 \\
Physiotherapy & $11.5 \%$ & 5 \\
Other & & \\
School of Osteopathy & $94 \%$ & 34 \\
Spanish & $6 \%$ & 2 \\
Other & 7 (mean) - 4.45 SD & \\
Experience (years) & & 34 \\
Type of patients & $94 \%$ & 17 \\
Musculoskeletal & $47 \%$ & 14 \\
Pediatrics & $38.8 \%$ & 12 \\
Obstetrics & $33.3 \%$ & 4 \\
Gynecologists & $11.1 \%$ & \\
Sports & & \\
\hline
\end{tabular}

However, more than one-third of patients treated in the Spanish public Health System for non-specific low back pain continue to suffer from pain 2 months after their first visit and in up to $10 \%$ of these individuals, the pain becomes worse [20]. In addition, the probability of referral to physical therapy or rehabilitation in Spain is greater when low back pain is more intense (acute and subacute cases) [20]. Given this situation, along with the perception of the usefulness of manipulative therapies in the treatment of back pain $[13,21]$, it may explain why this distress is the main cause for seeking osteopathic care (both in Spain and in other countries), and moreover, most patients included in our study reported chronicity in their complaints. This finding is contrary to what Burke et al. [6] and Fawkes et al. [7] reported, as they noted that acute cases (less than 46 weeks) were mostly treated. This difference in the early care environment may be related to the lack of a specific regulation the osteopathic scope of practice within the Spanish population.

Despite spine-related clinical problems, patients with headaches, facial-related pain and other symptoms are commonly seen by osteopaths $[9,10]$. In our survey, headaches were the 3rd most common reason for seeking osteopathic care (13\%). Some studies have shown preliminary positive results about the effectiveness of osteopathic manipulative treatment (OMT) in migraine patients [22-25]. Moreover, there is some evidence that OMT may lower the cost of the treatment regimen for patients with migraine headaches [26]. Notwithstanding this, according to the available literature, there is a low level of evidence that OMT is effective in the management of headache [27].

In our study, $69 \%$ of patients had previously visited a medical physician for the same complaint, with an average number of consultations before the start of the osteopathic treatment of 2.8. Actually, the pattern of CAM use for back pain supplementary to conventional care was evident across back pain-specific population studies from North America, Europe, and Australia, thereby suggesting that back pain sufferers did not choose CAM instead of conventional medicine [13].

The data obtained regarding the reduction of pain both after the first consultation and at the end of the treatment indicate that osteopathic care is a good approach to relieve patients' pain. Although the effectiveness of osteopathy for musculoskeletal pain has been disputed [28], several studies have shown its effectiveness in patients with both acute and chronic lower back pain [29-32], neck pain [33] and in other clinical presentations [24, 27, 34-39]. It is also worth highlighting the low percentage of adverse effects reported by the patients $(7 \%)$ at the end of treatment. These results reinforce those reported by Fawkes et al. [7] and Burke 
Table 7 Patients data compared to available literature data

\begin{tabular}{|c|c|c|c|c|c|c|}
\hline & $\begin{array}{l}\text { Cofenat et al. } \\
\text { (2008) [3] }\end{array}$ & $\begin{array}{l}\text { Burke et al. } \\
\text { (2013) [6] }\end{array}$ & $\begin{array}{l}\text { Fawkes et al. } \\
\text { (2013) [7] }\end{array}$ & $\begin{array}{l}\text { Wilkinson et al. } \\
(2015) \text { [9] }\end{array}$ & $\begin{array}{l}\text { van Dun et al. } \\
\text { (2016) [10] }\end{array}$ & $\begin{array}{l}\text { Alvarez Bustins et al. } \\
\text { (2018) (current study) }\end{array}$ \\
\hline $\begin{array}{l}\text { Average } \\
\text { age }\end{array}$ & $36-45$ & $30-50$ & 44.8 & 40.3 & 45 & 40 \\
\hline $\begin{array}{l}\text { Percentage } \\
\text { of women }\end{array}$ & >Women & $67.6 \%$ & $56 \%$ & $63 \%$ & & $61 \%$ \\
\hline $\begin{array}{l}\text { Percentage } \\
\text { of men }\end{array}$ & $<$ Men & $32.4 \%$ & $43 \%$ & $37 \%$ & & $39 \%$ \\
\hline $\begin{array}{l}\text { Reason for } \\
\text { consultation }\end{array}$ & - & $\begin{array}{l}\text { Lumbar, cervical, } \\
\text { EEll }\end{array}$ & $\begin{array}{l}\text { Lumbar, cervical, } \\
\text { pelvis }\end{array}$ & $\begin{array}{l}\text { Lumbar, Head-area, } \\
\text { facial, Cervical spine }\end{array}$ & $\begin{array}{l}\text { Cervical and } \\
\text { lumbar, } \\
\text { headache, } \\
\text { Cervical } \\
\text { brachialgia }\end{array}$ & $\begin{array}{l}\text { Cervical, lumbar, } \\
\text { Head and facial } \\
\text { area }\end{array}$ \\
\hline $\begin{array}{l}\text { Techniques } \\
\text { used } \\
\text { preferably }\end{array}$ & $\begin{array}{l}\text { Acupuncture, } \\
\text { yoga, Homeopathy, } \\
\text { massage }\end{array}$ & $\begin{array}{l}\text { Soft tissue, Muscle } \\
\text { Energy technique, } \\
\text { mobilization } \\
\text { techniques, } \\
\text { education }\end{array}$ & $\begin{array}{l}\text { Soft tissue, mobilization } \\
\text { techniques, HVT, } \\
\text { education, cranial, } \\
\text { Muscle Energy } \\
\text { technique, functional }\end{array}$ & $\begin{array}{l}\text { Cranial, soft tissue, } \\
\text { mobilization } \\
\text { techniques, } \\
\text { functional, } \\
\text { counterstrain, }\end{array}$ & Visceral, cranial & $\begin{array}{l}\text { Mobilization } \\
\text { techniques, soft } \\
\text { tissue techniques, } \\
\text { HVT, cranial } \\
\text { techniques }\end{array}$ \\
\hline
\end{tabular}

et al. [6] and other studies evaluating other manual therapies [40,41] and are consistent with systematic reviews assessing the adverse effects of manual therapies [42].

The average number of visits per patient was 3.6 visits, plus in more than half of the cases, treatment did not exceed 2 months. In light of these results, osteopathic care appears to be effective over a short period of time and with a relatively low number of sessions. Despite these results, the clinical effectiveness and economic assessment of osteopathic care has not been established by our study. Furthermore, a lack of evidence in the literature showing the cost-effectiveness of osteopathic treatment remains [43, 44]. However, the results note a high degree of patient satisfaction with osteopathic treatment. Beyond clinical outcomes, patient-centered care, which is also a key aspect within the osteopathic approach, has been proven to be one of the most promising and effective scopes within health care [45-47] for its major relevance towards the established therapeutic relationship, application of a holistic approach to solve patients' distress and tailoring of a patient's treatment based on their context [48].

\section{Limitations}

The main limitation of this study is the low response rate. Although a total of 61 professionals decided to participate, in only 59\% $(n=36)$ of the cases were data collected. The great heterogeneity of professional profiles and the undefined legal situation of the profession in Spain leads to poor cohesion in this sector. Moreover, the absence of a single official institution representing the professionals' interest and scope of practice, together with the differences among stakeholders, hinder the development of the profession and the performance of studies at population scale. Nonetheless, the significant number of patients included $(n=314)$ enables obtaining, at least, reliable associated indicators about the profile of patients treated with osteopathy in Spain.

Likewise, $83 \%$ of the datasets originated from a single region of the country (Catalonia) leading to a demographic bias of the results. Consequently, the data obtained on the professionals' profile (secondary aim) may not be fully representative and should therefore be analyzed and interpreted with caution. Despite some unpublished studies addressing this issue [49-51], there is still a lack of evidence regarding the professional profile in Spain. A new study to identify the professional profiles of Spanish osteopaths is currently being conducted based on previous experiences in Benelux [10] and Italy (in process).

Some other limitations arise from the methodology used to obtain the data. The SDC tool was developed and piloted in the UK and was used as faithfully as possible to the original version. The choice of the SDC tool responds to the will of using a validated tool, however, the osteopathic scope of practice in the Spain is different from that of UK and some questions may have different interpretation in the Spanish context. Additionally, the translation process of the questionnaire did not involve professional translators and only included a small pilot sample for testing of the final translation.

Finally, practitioners, rather than patients, were responsible for the data collection. Although written specific instructions were given to osteopaths (Additional file 2), no in-person training or quality control checks were performed to assure that the forms were completed accurately. This could be a source of potential bias towards favorable outcomes rather than all outcomes. Moreover, specifically those answers concerning ethics, good practices and patients' satisfaction should be considered under the light of potential reporting bias. 


\section{Conclusion}

This study describes the profile of patients who receive osteopathic care in Spain. By using a modified UK-developed SDC tool, data on the socio-demographic characteristics, population use habits, clinical characteristics and therapeutic experience of patients seeking osteopathic care in Spain were collected. Secondarily, information was obtained regarding the osteopathic management of patients and the way in which this service is provided. This is the first study conducted in Spain to analyze the profile of patients who receive osteopathic treatment. This information can help to increase public awareness of the profession, aid the decision-making process of patients regarding their care, and contribute to an understanding of the value that osteopathy may have in Spanish healthcare.

\section{Additional files}

Additional file 1: Supplementary file. Observatorio de las Terapias Naturales. (PDF 293 kb)

Additional file 2: Instructions to inform patients clearly and comprehensively about the purpose of the study. (ZIP $166 \mathrm{~kb}$ )

Additional file 3: Extended version of the SDC Tool, which was translated and cross-culturally adapted into Spanish. (ZIP 384 kb)

Additional file 4: Professional survey. A Survey containing 20 questions covering osteopaths' professional profile. (ZIP $172 \mathrm{~kb}$ )

\section{Abbreviations}

CAM: Complementary and alternative medicines; GPs: General practitioners; HVT: High Velocity technique/s; NCOR: National Council of Osteopathic Research; NRS: Numerical rating scale; SDC tool: Standardized data collection tool; SI: Sacro-ilíac joint; TMJ: Temporo-mandibular joint

\section{Acknowledgements}

The authors would like to thank NCOR for allowing us to use the SDC tool. We would also like to thank all of the participants who contributed their time to completing the surveys and the Registro de Osteópatas de España for their financial support.

The authors sincerely thank Francesco Cerritelli, Dr. Oliver Thomson and Dr. Jorge Esteves for reviewing the article as well as Albert Paredes for contributions during the early stages of the project.

\section{Funding}

Funding for this project was provided by the Registro de Osteópatas de España (ROE) grant program.

\section{Availability of data and materials}

The datasets used and/or analyzed during the current study are available from the corresponding author on reasonable request.

\section{Authors' contributions}

GA conceptualized and designed the study. All of the authors were responsible for adapting the SDC tool for the Spanish context and for data collection and interpretation. SR was responsible for data analysis. GA and SR contributed to data analysis and interpretation as well as critical review and revision of the manuscript. All of the authors contributed to drafting and critically revising the paper and agree to be accountable for all aspects of the work. All authors read and approved the final manuscript.

\section{Author's information}

Gerard Alvarez - PhD student on Biomedical Research Methodology and Public Health in the Medical Department of the Universitat Autònoma de Barcelona. (Barcelona (Spain)).

\section{Ethics approval and consent to participate}

The Institutional Review Board of Barcelona Osteopathic Foundation approved the study (FOB04140001). Informed consent was assumed by participation in the study.

\section{Consent for publication}

Not applicable.

Competing interests

The authors declare that they have no competing interests.

\section{Publisher's Note}

Springer Nature remains neutral with regard to jurisdictional claims in published maps and institutional affiliations.

\section{Author details}

${ }^{1}$ Centre for Osteopathic Medicine - C.O.ME. Collaboration, Spain National Center, Clinical-based Human Research Department, Barcelona, Spain. ${ }^{2}$ Iberoamerican Cochrane Centre - Biomedical Research Institute Sant Pau, IIB Sant Pau, Barcelona, Spain. ${ }^{3}$ Blanquerna School of Health Sciences, Ramon Llull University, Barcelona, Spain. ${ }^{4}$ Fundació d'Osteopatia de Barcelona, Grup de Recerca en Osteopatia de Barcelona, Sant Just Desvern, Barcelona, Spain.

Received: 12 May 2017 Accepted: 26 March 2018

Published online: 11 April 2018

\section{References}

1. Tricot P, Puig JB. OSTEOPATÍA. una Terapia Por Descubrir. Editorial Paidotribo; 2006.

2. $\quad$ van Dun P, Wagner C. Die Identität der Osteopathie in Europa. Osteopathische Medizin. 2012;13(4):22-6. https://doi.org/10.1016/S16159071(12)60062-8.

3. COFENAT, CONAMAD, TENACAT. Observatorio de las Terapias Naturales. Published May 1, 2008. Accessed 6 May 2017.

4. Ministerio de Sanidad, Política Social e lgualdad. Análisis de la situación de las terapias naturales. http://www.mspsi.gob.es/novedades/docs/ analisisSituacionTNatu.pdf. Published December 19, 2011. Accessed 6 May 2017.

5. Fawkes C, Leach J, Matias S, Moore A. The standardised data collection project. Standardised data collection within osteopathic practice in the UK: development and first use of a tool to profile osteopathic care in 2009. East Sussex: National Council for osteopathic research (NCOR) university of Brighton; 2010.

6. Burke SR, Myers R, Zhang AL. A profile of osteopathic practice in Australia 2010-2011: a cross sectional survey. BMC Musculoskelet Disord. 2013;14(1): 227. https://doi.org/10.1186/1471-2474-14-227.

7. Fawkes CA, Leach CMJ, Mathias S, Moore AP. A Profile of osteopathic care in private practices in the United Kingdom: a national pilot using standardised data collection. Man Ther. 2013;19(2):125-30. https://doi.org/ 10.1016/j.math.2013.09.001

8. Morin C, Aubin A. Primary reasons for osteopathic consultation: a prospective survey in Quebec. PLoS One. 2014;9(9):e106259. https://doi.org/ 10.1371/journal.pone.0106259.

9. Wilkinson J, Thomas KJ, Freeman JV. Day-to-day practice of osteopaths using osteopathy in the cranial field, who are affiliated with the Sutherland Cranial College of Osteopathy (SCCO): a national survey. Int J Osteopath Med. 2015;18(1):13-21. https://doi.org/10.1016/j.ijosm. 2014.04.008.

10. van Dun P, Nicolaie MA, Van Messem A. State of affairs of osteopathy in the Benelux: Benelux Osteosurvey 2013. Int J Osteopath Med. 2016;20:3-17. https://doi.org/10.1016/j.ijosm.2016.01.003.

11. Hawker GA, Mian S, Kendzerska T, French M. Measures of adult pain: visual analog scale for pain (VAS pain), numeric rating scale for pain (NRS pain), McGill pain questionnaire (MPQ), short-form McGill pain questionnaire (SF$M P Q)$, chronic pain grade scale (CPGS), short Form-36 bodily pain scale (SF36 BPS), and measure of intermittent and constant osteoarthritis pain (ICOAP). Arthritis Care Res (Hoboken). 2011;63(Suppl 11):S240-52. https://doi. org/10.1002/acr.20543.

12. Ryan A, Wilson S, Taylor A, Greenfield S. Factors associated with self-care activities among adults in the United Kingdom: a systematic review. BMC Public Health. 2009;9:96. https://doi.org/10.1186/1471-2458-9-96. 
13. Murthy $\mathrm{V}$, Sibbritt DW, Adams J. An integrative review of complementary and alternative medicine use for back pain: a focus on prevalence, reasons for use, influential factors, self-perceived effectiveness, and communication. Spine J. 2015;15(8):1870-83. https://doi.org/10.1016/j.spinee.2015.04.049.

14. Vlieger AM, van de Putte EM, Hoeksma H. The use of complementary and alternative medicine in children at a general paediatric clinic and parental reasons for use. Ned Tijdschr Geneeskd. 2006;150(11):625-30.

15. Low E, Murray DM, O'Mahony O, O'B Hourihane J. Complementary and alternative medicine use in Irish paediatric patients. Ir J Med Sci. 2008;177(2): 147-50. https://doi.org/10.1007/s11845-008-0152-0.

16. Hameen-Anttila KP, Niskala UR, Siponen SM, Ahonen RS. The use of complementary and alternative medicine products in preceding two days among Finnish parents - a population survey. BMC Complement Altern Med. 2011;11(1):107. https://doi.org/10.1186/1472-6882-11-107.

17. Posadzki P, Watson L, Alotaibi A, Ernst E. Prevalence of complementary and alternative medicine (CAM)-use in UK paediatric patients: a systematic review of surveys. Complement Ther Med. 2013;21(3):224-31. https://doi. org/10.1016/j.ctim.2012.11.006.

18. Fernández-de-las-Peñas C, Alonso-Blanco C, Hernández-Barrera V, PalaciosCeña D, Jiménez-García R, Carrasco-Garrido P. Has the prevalence of neck pain and low back pain changed over the last 5 years? A population-based national study in Spain. Spine J. 2013;13(9):1069-76. https://doi.org/10.1016/ j.spinee.2013.02.064.

19. Palacios-Ceña D, Alonso-Blanco C, Hernández-Barrera V, Carrasco-Garrido P Jiménez-García R, Fernández-de-las-Peñas C. Prevalence of neck and low back pain in community-dwelling adults in Spain: an updated populationbased national study (2009/10-2011/12). Eur Spine J. 2015;24(3):482-92. https://doi.org/10.1007/s00586-014-3567-5.

20. Kovacs FM, Fernández C, Cordero A, et al. Non-specific low back pain in primary care in the Spanish National Health Service: a prospective study on clinical outcomes and determinants of management. BMC Health Serv Res. 2006;6:57. https://doi.org/10.1186/1472-6963-6-57.

21. Ong C-K, Doll H, Bodeker G, Stewart-Brown S. Use of osteopathic or chiropractic services among people with back pain: a UK population survey. Health Soc Care Community. 2004;12(3):265-73.

22. Voigt K, Liebnitzky J, Burmeister $U$, et al. Efficacy of osteopathic manipulative treatment of female patients with migraine: results of a randomized controlled trial. J Altern Complement Med. 2011;17(3):225-30. https://doi.org/10.1089/acm.2009.0673.

23. Adragna V, Bertino AS, Carano M, Soru A, Taranto G, Desideri R. 0052 Migraine without aura and osteopathic medicine, a non-pharmacological approach to pain and quality of life: open pilot study. J Headache Pain. 2015;16(S1):127. https://doi.org/10.1186/1129-2377-16-S1-A180.

24. Cerritelli F, Ginevri L, Messi G, et al. Clinical effectiveness of osteopathic treatment in chronic migraine: 3-armed randomized controlled trial. Complement Ther Med. 2015;23(2):149-56. https://doi.org/10.1016/j.ctim.2015.01.011.

25. D'Ippolito M, Tramontano M, Buzzi MG. Effects of osteopathic manipulative therapy on pain and mood disorders in patients with high-frequency migraine. J Am Osteopath Assoc. 2017;117(6):365-9. https://doi.org/10.7556/jaoa.2017.074.

26. Schabert E, Crow WT. Impact of osteopathic manipulative treatment on cost of care for patients with migraine headache: a retrospective review of patient records. J Am Osteopath Assoc. 2009;109(8):403-7.

27. Cerritelli F, Lacorte E, Ruffini N, Vanacore N. Osteopathy for primary headache patients: a systematic review. JPR. 2017;Volume 10:601-11. https://doi.org/10.2147/JPR.S130501.

28. Posadzki P, Ernst E. Osteopathy for musculoskeletal pain patients: a systematic review of randomized controlled trials. Clin Rheumatol. 2011; 30(2):285-91. https://doi.org/10.1007/s10067-010-1600-6.

29. Franke H, Franke J-D, Fryer G. Osteopathic manipulative treatment for nonspecific low back pain: a systematic review and meta-analysis. BMC Musculoskelet Disord. 2014;15(1):286-18.

30. Majchrzycki M, Wolski H, Seremak-Mrozikiewicz A, et al. Application of osteopathic manipulative technique in the treatment of back pain during pregnancy. Ginekol Pol. 2015;86(3):224-8.

31. Schwerla F, Rother K, Rother D, Ruetz M, Resch K-L. Osteopathic manipulative therapy in women with postpartum low back pain and disability: a pragmatic randomized controlled trial. J Am Osteopath Assoc. 2015;115(7):416-25. https://doi.org/10.7556/jaoa.2015.087.

32. Licciardone JC, Gatchel RJ, Aryal S. Recovery from chronic low back pain after osteopathic manipulative treatment: a randomized controlled trial. J Am Osteopath Assoc. 2016;116(3):144-55.
33. Franke H, Franke J-D, Fryer G. Osteopathic manipulative treatment for chronic nonspecific neck pain: a systematic review and meta-analysis. Int J Osteopath Med. 2015;18(4):255-67. https://doi.org/10.1016/j.jjosm.2015.05.003.

34. Dunning JR, Butts $R$, Mourad F, et al. Upper cervical and upper thoracic manipulation versus mobilization and exercise in patients with cervicogenic headache: a multi-center randomized clinical trial. BMC Musculoskelet Disord. 2016;17(1):64. https://doi.org/10.1186/s12891-016-0912-3.

35. Hubert D, Soubeiran L, Gourmelon F, et al. Impact of osteopathic treatment on pain in adult patients with cystic fibrosis-a pilot randomized controlled study. PLoS One. 2014;9(7):e102465.

36. Muller A, Franke $H$, Resch K-L, Fryer G. Effectiveness of osteopathic manipulative therapy for managing symptoms of irritable bowel syndrome: a systematic review. J Am Osteopath Assoc. 2014;114(6):470-9. https://doi. org/10.7556/jaoa.2014.098.

37. Swender DA, Thompson G, Schneider K, McCoy K, Patel A. Osteopathic manipulative treatment for inpatients with pulmonary exacerbations of cystic fibrosis: effects on spirometry findings and patient assessments of breathing, anxiety, and pain. J Am Osteopath Assoc. 2014;114(6):450-8. https://doi.org/10.7556/jaoa.2014.095.

38. Cerritelli F, Pizzolorusso G, Renzetti C, et al. A multicenter, randomized, controlled trial of osteopathic manipulative treatment on preterms. Rubens C. PLoS One. 2015;10(5):e0127370. https://doi.org/10.1371/journal.pone. 0127370.

39. Ruffini N, D'Alessandro G, Cardinali L, Frondaroli F, Cerritelli F. Osteopathic manipulative treatment in gynecology and obstetrics: a systematic review. Complement Ther Med. 2016:26:72-8. https://doi.org/10.1016/j.ctim.2016.03.005.

40. Paanalahti K, Holm LW, Nordin M, Asker M, Lyander J, Skillgate E. Adverse events after manual therapy among patients seeking care for neck and/or back pain: a randomized controlled trial. BMC Musculoskelet Disord. 2014; 15(1):1-10.

41. Todd AJ, Carroll MT, Robinson A, Mitchell EKL. Adverse events due to chiropractic and other manual therapies for infants and children: a review of the literature. J Manip Physiol Ther. 2015;38(9):699-712.

42. Carnes D, Mars TS, Mullinger B, Froud R, Underwood M. Adverse events and manual therapy: a systematic review. Man Ther. 2010;15(4):355-63. https:// doi.org/10.1016/j.math.2009.12.006.

43. Steel A, Sundberg $T$, Reid R, et al. Osteopathic manipulative treatment: a systematic review and critical appraisal of comparative effectiveness and health economics research. Musculoskelet Sci Pract. 2017;27:165-75. https:// doi.org/10.1016/j.math.2016.10.067.

44. Licciardone JC. Systematic review of comparative effectiveness and health economics research relating to osteopathic manipulative treatment. Musculoskelet Sci Pract. 2017;29:e16-7. https://doi.org/10.1016/j.msksp.2017.01.006.

45. Parsons S, Harding G, Breen A, et al. The influence of patients" and primary care practitioners" beliefs and expectations about chronic musculoskeletal pain on the process of care: a systematic review of qualitative studies. Clin J Pain. 2007;23(1):91-8.

46. Luxford K, Safran DG, Delbanco T. Promoting patient-centered care: a qualitative study of facilitators and barriers in healthcare organizations with a reputation for improving the patient experience. Int J Qual Health Care. 2011;23(5):510-5. https://doi.org/10.1093/intqhc/mzr024.

47. Dwamena F, Holmes-Rovner M, Gaulden CM, et al. Interventions for providers to promote a patient-centred approach in clinical consultations. Cochrane Database Syst Rev. 2012;12:CD003267. https://doi.org/10.1002/ 14651858.CD003267.pub2.

48. Orrock PJ. The patient experience of osteopathic healthcare. Man Ther. 2016;22(C:131-7. https://doi.org/10.1016/j.math.2015.11.003.

49. Alzuri AG. Osteopaths in Spain: a survey of training and practice patterns. (thesis dissertation) European School of Osteopathy. 2003.

50. Brea JV. Exploring the identity of the osteopaths in Spain. A survey study. (thesis dissertation) European School of Osteopathy. 2012.

51. Cano S. Osteopathy in Spain: a survey to explore the practice characteristics, training, and attitudes towards regulation. (thesis dissertation) London School of Osteopathy. 2014. 